\title{
Desdobramentos territoriais da hipercapilaridade dos serviços financeiros digitais: o pagamento automático de pedágios no Brasil
}

\author{
Territorial aspects of the hyper capillarity of digital financial services: automatic toll payment in Brazil
}

\author{
Fernando Guilherme Silveira Manocchio $\bowtie$ (I) , Bruno Moreira Riani Costa $\bowtie$ (I), \\ Fabrício Gallo* $\triangle$ (1D
}

Instituto de Geociências e Ciências Exatas, Universidade Estadual Paulista Júlio de Mesquita Filho, Rio Claro, São Paulo, Brasil

E-mail: fernando.manocchio@unesp.br (FGSM); bruno.riani@unesp.br (BMRC)

*E-mail para correspondência: fabricio.gallo@unesp.br
Recebido (Received): 12/04/2021 Aceito (Accepted): 23/08/2021

Resumo: Neste artigo propõe-se discutir brevemente a evolução e a recente popularização dos pagamentos móveis no Brasil, em conjunto com o entendimento das relações entre as novas formas digitais e eletrônicas dos serviços financeiros com o crescimento das empresas de pagamento automático de pedágios em rodovias concedidas à iniciativa privada. Parte-se do pressuposto de que o objeto de estudo da geografia é o espaço geográfico, que pode ser brevemente definido enquanto conjunto indissociável de sistemas de objetos e sistemas ações. Além disso, entende-se que atualmente, no período técnico-científico-informacional, a informação é um vetor chave que orienta as ações. Estes são conceitos basilares que norteiam nosso método de interpretação. De acordo com os resultados obtidos, nota-se que as cinco principais empresas de pagamento eletrônico de pedágios sobre as quais a pesquisa se debruça - Sem Parar, ConectCar, Move Mais, Veloe e Taggy - apresentam crescimento nos últimos anos e buscam uma dupla expansão: de mercado, sendo um produto interessante mesmo para motoristas que não precisam trafegar por rodovias pedagiadas constantemente, e de função, se aproximando das empresas de pagamentos móveis de modo geral. Por fim, entende-se que essas novas formas de pagamentos móveis e digitais podem repercutir de múltiplas maneiras nos usos do território brasileiro na contemporaneidade.

Palavras-chaves: Pagamentos móveis; Concessões rodoviárias; Finanças digitais.

Abstract: In this paper we propose to discuss the evolution and the recent popularization of mobile payments in Brazil together with the understanding of the relationships between the new digital and eletronic forms of financial services with the growth of automatic toll payment companies. We start from the assumption that the object of study of geography is geographic space, wich can be briefly defined as an inseparable set of system of objects and action systems. In addition, we understand that currently, in the technical-scientificinformational period, information is a vector that guide actions. These are basic concepts that guide our method of interpretation. According to our results, the five main electronic toll payment companies that we focus - Sem Parar, ConectCar, Move Mais, Veloe and Taggy - have shown growth in recent years while looking for a double expansion: market, being an interesting product for drivers who do not need to travel on roads constantly, as a function, approaching mobile payment companies in general. Finally, we understand that these new forms of mobile and digital payments can have multiple repercussions on the uses of the territory.

Keywords: Mobile payment; Road concessions; Digital finance.

\section{Introdução}

Não é novidade que a tecnologia se faz cada vez mais presente na vida cotidiana, seja através de computadores, notebooks, tablets ou smartphones. Com a evolução tecnológica e informacional que presenciamos atualmente, o acesso às notícias e informações é cada vez mais rápido e, às vezes, instantâneo. Nos utilizamos dessas ferramentas para a execução de diversas atividades, que vão do uso banal, como 
acesso a conteúdos corriqueiros, ao uso mais cuidadoso e refinado, como a realização de compras e transações financeiras através de aplicativos e plataformas digitais.

Ao longo dos últimos anos os serviços financeiros digitais vêm apresentando altas taxas de crescimento e isso se efetiva tanto com o internet banking como também com o mobile banking. Tendo em vista este cenário, não são apenas os bancos tradicionais que aumentaram seus esforços na elaboração e desenvolvimento de sites e aplicativos que visam facilitar os serviços financeiros em âmbito virtual. Muitos bancos digitais, fundados recentemente, e fintechs, empresas de tecnologia e inovação voltadas ao mercado financeiro e que funcionam sem agências presenciais, exercem papel de vanguarda no que diz respeito aos serviços financeiros e ao modo como se dá o relacionamento entre instituição bancária e cliente.

A importância que os canais digitais de serviços bancários e financeiros apresentaram nos últimos anos pode ser ilustrada através do relatório mais recente de tecnologia bancária da Federação Brasileira de Bancos (FEBRABAN). Em 2019 as transações bancárias nos canais tradicionais mantiveram seus volumes, mas caíram em participação total, enquanto as operações bancárias via mobile banking aumentaram em volume e também em participação total, de modo que o canal mobile se transformou em uma ferramenta fundamental para a realização de transações e contratações de produtos, além de operações em investimentos e seguros (FEBRABAN, 2019).

Em suma, a expansão dos serviços bancário-financeiros através dos smartphones pode contribuir com os avanços de uma nova etapa da expansão financeira sobre o território usado (SANTOS et al., 2000). Assim, a partir da análise desse novo processo é possível destacar e compreender etapas renovadas do fenômeno que Contel (2006) discutiu sobre a hipercapilaridade das finanças.

Entendemos que as dinâmicas financeiras digitais seguem se capilarizando de modos distintos e causando uma série de impactos no território nacional. Nesse sentido, concordamos com a afirmação de Warf (2017, p. 402) de que "o dinheiro digital pode parecer abstrato e etéreo, mas suas consequências no mundo concreto são muito reais".

Destarte, temos como objetivo para este artigo analisar as relações entre os pagamentos e as transações via dispositivos móveis e, por consequência, a evolução do mobile payment e do mobile banking no Brasil, além das aproximações entre eles e o desenvolvimento das empresas de pagamento automático de pedágios. Em resumo, buscamos discutir sobre a evolução dos serviços financeiros digitais em conjunto com a expansão das cinco principais empresas de pagamento automáticos de pedágios que atuam no Brasil - Sem Parar, ConectCar, Veloe, Move Mais, Veloe e Taggy. Para tal, concentraremos nossos esforços em dois casos centrais, Taggy e Veloe, pois apresentam particularidade que, segundo nossa leitura, devem ser ressaltadas.

\section{Os serviços financeiros digitais}

No Brasil os serviços bancários digitais começaram a apresentar um crescimento relevante a partir de 2013, sendo impulsionados principalmente pelo maior acesso aos telefones celulares, como apontam alguns relatórios da FEBRABAN (2013), dinamizando os serviços bancários (principalmente o mobile banking) e financeiros em âmbito digital, nesse sentido destaca-se a evolução dos pagamentos móveis no país.

Sobre o mobile payment, Cernev (2010, p. 125) aponta que este pode ser definido como o conjunto de "pagamentos realizados e/ou viabilizados por meio de tecnologias de mobilidade digital, via dispositivos móveis. Diversos são os modelos de pagamentos móveis atualmente adotados em todo o mundo". Nota-se que a definição apresentada pelo autor é abrangente e permite aproximações com os dispositivos de pagamento automático de pedágios e serão discutidas posteriormente.

Julgamos necessário apresentar as diferenças entre o internet e o mobile banking. Conforme exposto, ambos são canais digitais dos meios de serviços bancários e guardam diversas semelhanças. No entanto, o acesso ao mobile banking se dá através dos aplicativos e plataformas presentes em telefones celulares, enquanto o internet banking tem seu acesso realizado por meio da função web, em computadores e notebooks. Na perspectiva de Contel (2006, p. 262), o internet banking, além de apresentar uma alta capilaridade, tem seus custos diminuídos na transação dos produtos e serviços oferecidos por conta da utilização da plataforma web. Entendemos que os mesmos princípios, de redução dos custos e alta capilaridade, se aplicam também ao canal mobile, dada a disseminação dos telefones celulares no momento atual.

Com o objetivo de demonstrar a importância dos pontos discutidos, retomamos alguns números do relatório de pesquisa em tecnologia bancária da Federação Brasileira de Bancos (FEBRABAN) (Figura 1). O volume de transações financeiras realizadas através de smartphones foi 31,3 bilhões em 2018 - alcançando 
um crescimento relevante se considerarmos os 18,6 bilhões registrados em 2016. Além disso, no ano de 2018 o mobile banking aumentou sua parcela de participação no total de transações bancárias para $40 \%$ do total e o número de transações com movimentações financeiras por esse canal atingiu um crescimento de $80 \%$ em relação ao ano anterior. Ademais, apenas no ano de 2018 foram abertas 2,5 milhões de contas bancárias pelo celular (número 56\% maior em relação ao ano anterior), enquanto o número de contas abertas via internet banking foi de 26 mil em 2017 para 434 mil em 2018. Por fim, um dado interessante diz respeito ao número de heavy users (clientes que realizam $80 \%$ ou mais de suas atividades pelo mesmo canal, nesse caso em específico o mobile banking), que passou de 16,3 milhões no ano de 2017 para 27 milhões em 2018 (FEBRABAN, 2019).

Figura 1: Número de transações bancárias via Mobile Banking e a participação do canal na composição total de transações no Brasil



Fonte: Pesquisas FEBRABAN de Tecnologia Bancária.

De acordo com o gráfico 1, nos últimos anos as transações financeiras e os serviços bancários acessados através do mobile banking têm representado uma fatia cada vez maior do número total de operações bancárias. No ano de 2015 o canal supracitado era responsável por 11,2 bilhões de transações, valor que representava apenas $20 \%$ do total. Nos dias atuais, esse mesmo canal representa $44 \%$ de todas as operações realizadas e é responsável por 39,4 bilhões de transações bancárias.

Além disso, um ponto de destaque está no fato de que, atualmente, a expansão das finanças em âmbito virtual não se dá apenas pela atuação dos bancos tradicionais. Cada vez mais nota-se uma série de outros agentes, como é o caso dos bancos digitais e das fintechs, startups do setor financeiro, que desempenham um duplo papel de concorrência e cooperação com os atores tradicionais (VIDEIRA, 2020). É comum, sobretudo no ramo das empresas de pagamento automático de pedágio, que as fintechs de maior destaque sejam rapidamente incorporadas ao portfólio de pagamentos de grandes grupos econômicos - que se dá através da entrada desses grupos na estrutura acionária das empresas.

Seguramente, o crescimento desses novos modos digitais e automáticos de acesso aos serviços e produtos financeiros se deve ao desenvolvimento e difusão do meio técnico-científico-informacional e à incorporação da informação, enquanto vetor fundamental, ao território brasileiro (SANTOS, 2002). É através disso que as finanças alcançam níveis crescentes de penetração e seguem encontrando formas de dinamização. Por via de consequência, os produtos e serviços financeiros tornam-se cada vez mais próximos dos usuários, estando sua contratação condicionada a apenas alguns cliques na tela do telefone celular.

A expansão tecnológica atual permite uma série de possibilidades para diferentes usos do território. Com a popularização dos telefones celulares e das redes de telefonia, diversos produtos foram impulsionados, sobretudo os bancários e financeiros - que encontram nas plataformas virtuais uma forma de serem oferecidos de maneira extremamente capilarizada. Soma-se a isso as grandes alterações que o processo causou nas formas de relacionamento entre banco (seja ele novo ou tradicional) e pessoas bancarizadas. 
Sem dúvidas o smartphone é um elemento central nessa discussão, pois é ele quem se apresenta como mediador desse processo. São os telefones celulares que permitem e alavancam essa maior capilaridade no período atual. Nas palavras de Bertollo (2019, p. 64)

O uso do smartphone impõe uma nova lógica de informatização do território, e seu uso passa necessariamente pela ciência e pela técnica, pela instalação de novas infraestruturas que se articulam em sistemas de redes e pela política e pela economia na determinação desse objeto e a informatização que ele proporciona supõem o uso do território mais fortemente ligado à informação (BERTOLLO, 2019, p. 64).

$\mathrm{Na}$ esteira desse raciocínio, entendemos que os meios digitais dos serviços bancários exigem um determinado grau de densidade em técnicas da informação, mesmo que estas estejam distribuídas de modo desigual pelo território, como é o caso brasileiro. Desse modo, o estudo dos processos supracitados nos dão importantes instrumentos analíticos para o desenvolvimento da nossa proposta, que consiste em uma investigação acerca da popularização das empresas de pagamentos móveis em conjunto com as empresas de pagamento automático de pedágios. Assim, buscaremos compreender as relações entre essa forma de pagamento específica com a evolução dos pagamentos digitais como um todo, posto que o território brasileiro apresenta algumas zonas densas e outras rarefeitas no que diz respeito às materialidades e técnicas da informação (SANTOS e SILVEIRA, 2006).

Em rigor, essas formas digitais e inovadoras de pagamento se tornam possíveis graças ao atual estágio de desenvolvimento das técnicas, da ciência, da utilização da informação como vetor chave e da instrumentalização do território. Este período técnico-científico-informacional (SANTOS, 2002) se impõe, principalmente, a partir dos anos 1970 e se diferencia das definições propostas anteriormente (meio natural e meio técnico) pela profunda relação entre técnica e ciência, ou simplesmente tecnociência - que se dá sob os interesses do mercado. Todavia, cabe ressaltar que o meio não é apenas técnico e científico, e a informação deve ser considerada como uma variável essencial para o entendimento desse período, pois desempenha um papel central. Nas palavras de Milton Santos

Podemos falar então de uma cientificização e de uma tecnicização da paisagem. Por outro lado, a informação não apenas está presente nas coisas, nos objetos técnicos que formam o espaço, como ela é necessária à ação realizada sobre essas coisas. A informação é o vetor fundamental do processo social e os territórios são, desse modo, equiparados para facilitar a sua circulação (SANTOS, 2002, p. 239).

A partir disso, como explicitado pelo autor, o meio técnico-científico-informacional deve ser compreendido como a expressão geográfica do processo de globalização, que repercute das mais diversas maneiras nos diferentes campos do conhecimento, sejam eles econômicos, sociais e/ou culturais. Afinal, foi apenas no findar do século passado que todos os territórios do globo passaram a funcionar com certo grau de unicidade técnica e sob uma lógica única de abrangência universal.

Sobre a globalização atual, vista como ápice do processo de mundialização capitalista, pode-se dizer que existem quatro pautas principais no que diz respeito aos intentos de sua definição. A primeira delas é a unicidade da técnica, que diz respeito à relevância das técnicas da informação; é a partir disso que se faz possível a aceleração dos processos históricos, bem como permite a simultaneidade das ações ao redor de todo o mundo. A segunda é a cognoscibilidade do planeta, que pode ser traduzida como um saber aprofundado e extensivo de toda a superfície terrestre, cuja função é contribuir com o fornecimento de dados e estatísticas para as mais diversas decisões operacionais, fator que favorece um uso cada vez mais seletivo e pontual dos territórios. O terceiro aspecto é a convergência dos momentos, que sustenta exclusividades e privilégios nos diferentes usos do território. Por fim, mas não menos importante, a quarta característica é a existência de um motor único, que trabalha em função da extração da mais valia universal (SANTOS, 2001).

As consequências do processo de globalização são inúmeras e repercutam das mais diversas formas nos diferentes territórios - como já apontado anteriormente. Entretanto, aquela que mais nos interessa diz respeito ao processo de mundialização das finanças e, consequentemente, o impulsionamento dos serviços bancário-financeiros digitais através de plataformas na web e aplicativos em dispositivos móveis, que tem assumido um protagonismo crescente e se constituído em um importante fenômeno para os desdobramentos econômicos, políticos e territoriais.

Na perspectiva de Chesnais (2000), o mercado pode ser entendido como uma concentração de capitais industriais e financeiros, cujo poder é crescente, pois são privilegiados pela capacidade de atuação em escala 
global. Em outras palavras, o alcance e a extensão possibilitados pela globalização tornaram as finanças altamente fluidas e universais. Os investidores institucionais - sociedades financeiras, companhias de securitização, mutual funds e fundos de pensão - são agentes centrais em todos esses desdobramentos, afinal de contas, são estes alguns dos principais beneficiados por essa nova configuração do sistema capitalista.

Vale destacar que o avanço do processo de mundialização financeira também está relacionado aos avanços dos pressupostos neoliberais que ganharam força ao longo dos anos 1970 para se contrapor aos pressupostos keynesianos, predominantes no período após a segunda guerra mundial. Na leitura de Harvey (2008), essa virada neoliberal, que teve como principais expoentes Margareth Thatcher (primeira-ministra britânica) e Ronald Reagan (presidente dos Estados Unidos), foi fundamental para a reconstrução do poder de classe das elites econômicas. Segundo o autor, talvez o processo de neoliberalização não tenha sido muito efetivo no intento de revitalização dos processos de acumulação do capital global, porém teve notável sucesso na restauração, e até mesmo na criação, do poder das elites econômicas - fato que deu respaldo aos avanços do neoliberalismo. Outro marco de extrema importância para a universalização e autonomia das finanças foi o Consenso de Washington, realizado no ano de 1989. Dentre as principais consequências que se deram a partir das muitas recomendações de cunho neoliberal elaboradas no acordo, cabe destacar as privatizações, a redução da máquina estatal, a abertura comercial (sobretudo dos países latino-americanos), as políticas de liberalização financeira e a desregulamentação dos mercados nacionais. Destarte, com os avanços dos pressupostos neoliberais em detrimento do consenso keynesiano, as finanças começaram seu processo irrefreável de internacionalização.

Além da densidade técnica e informacional fixada ao território, produtos da globalização que fatalmente viabilizam tais eventos, é necessário destacar também o papel ativo da tecnosfera e da psicosfera (SANTOS, 2002) ao redor desse tema. A tecnosfera se instala no território para substituir o meio técnico e natural que preexistia, trabalhando fundamentalmente na realização dos interesses de agentes hegemônicos (geralmente construídos distantes do local), enquanto a psicosfera, lócus das ideias, trabalha em função de fornecer um sentido razoável às ações pensadas por tais agentes. Desse modo, psicosfera e tecnosfera atuam conjuntamente no local, mas sempre em favor de lógicas externas que não dizem respeito ao local e sim aos interesses globais de certos atores (SANTOS, 2002, p. 25).

Ainda sobre a psicosfera, que pode ser entendida campo das crenças ou espírito de uma época (KAHIL, 2013), compreendemos que esta se constitui em uma forma imaterial de convencimento. No caso aqui trabalhado, nota-se uma psicosfera da eficiência e da desburocratização financeira, majoritariamente representada pelas facilidades do uso do canal mobile ofertados pelos bancos tradicionais e também pela atuação, sobretudo através do marketing, dos bancos digitais e startups financeiras, que atuam com custos reduzidos e seguem angariando cada vez mais clientes, principalmente entre o público recém-bancarizado, que se caracteriza como público-alvo destas instituições. Sem embargo, é importante relacionar as formas materiais e imateriais que viabilizam este fenômeno, retomando a ideia de indissociabilidade entre objetos e ações.

Nos deparamos, de modo recorrente, que uma das características centrais na definição de fintechs principais empresas atuantes no ramo dos pagamentos móveis - é a ausência de clareza nos quadros regulatórios (VIDEIRA, 2020; ALBUQUERQUE, DINIZ, CERNEV, 2015). Entendemos que isso diz respeito às empresas recém-criadas, porém essa falta de clareza nos aspectos regulatórios pode ser um aspecto que reforça as características de autonomia e fluidez do mundo das finanças no momento atual. Nesse sentido, a regulação e as normas que regem o território tem um peso central para os avanços desses novos usos financeiros e digitais, o momento atual não só impulsiona novas formas de regulação como também necessita delas.

Segundo Videira (2020, p. 272) a "proposta das fintechs é trabalhar para inovar e otimizar serviços financeiros, deixando de lado a burocracia colocada pelos bancos tradicionais e apresentando valores muito reduzidos pelos serviços oferecidos". O motivo central das fintechs contarem com baixos custos de operação se dá por conta da utilização das plataformas digitais e da eficiência tecnológica, em detrimento da necessidade de agências físicas. Entretanto, é necessário ressaltar que essas empresas de tecnologia financeira cumprem um papel de concorrência, mas também se apresentam como importantes aliadas dos agentes financeiros tradicionais, portando assim um duplo papel de cooperação e concorrência.

O caso do Sem Parar nos ajuda a compreender esse duplo papel desempenhado por muitas fintechs. A empresa pioneira do ramo de pagamento automático de pedágios no Brasil foi criada no ano 2000 e recentemente, mais precisamente no ano de 2016 quando a empresa já tinha seu valor de mercado avaliado acima de US\$ 1 bilhão, vendida ao grupo norte-americano Fleetcor Technologies - empresa do ramo de pagamentos que atua em escala mundial - que pagou $\mathrm{R} \$ 4$ bilhões para compor integralmente a estrutura 
acionária da empresa. Cabe pontuar que a expansão de mercado desenvolvida pela empresa, que vai muito além do que o simples pagamento de pedágios, foi fundamental para que houvesse interesse do grupo norteamericano em realizar a compra.

As fintechs se caracterizam como startups do mercado financeiro. Atualmente essas empresas permitem que serviços cuja contratação outrora demandava presença física em agências bancárias - tais como abertura e gerenciamento de conta, assim como pagamentos em geral - passem a ser extremamente simples e rápidos, realizáveis via computador e telefones celulares. Levando em consideração apenas o ano de 2017, no Brasil o número de startups centradas no mercado financeiro cresceu $41 \%$. De modo geral, essas startups idealizadas no Brasil que atuam no mercado financeiro podem ser divididas basicamente em dez grandes grupos: I) pagamentos e transferências; II) gestão financeira empresarial; III) crédito; IV) crowdfunding (empresas de financiamento coletivo); V) criptomoedas; VI) seguros; VII) identidade; VIII) investimentos; IX) bancos digitais e; X) planejamento e finanças pessoais (JORGE et al., 2018, p.8).

No Brasil, a discussão sobre o tema ainda é recente e, apesar de presenciarmos o nascimento de diversas startups e fintechs, não são muitas as empresas já consolidadas no ramo dos pagamentos móveis - de mesmo modo que ainda são poucos os trabalhos em geografia discutindo amplamente sobre o tema. No campo acadêmico destacam-se, principalmente, as pesquisas em administração que versam sobre a aceitação desses novos meios tecnológicos por parte dos usuários (ABRAHÃO, 2015; MOLNAR NETO, 2013).

Nesse sentido, citar a situação chinesa é inevitável. A China, uma das principais potências econômicas e tecnológicas, tem, pelo menos, dois aplicativos extremamente populares e relevantes no que diz respeito aos pagamentos digitais, são eles o WeChat Pay e o AliPay. Curiosamente, o WeChat nasceu como uma ferramenta de comunicação instantânea e, posteriormente, incorporou funções de pagamentos e transferências financeiras ao aplicativo. Já o AliPay, do grupo Alibaba, tem suas origens voltadas ao comércio e as transações financeiras.

Além das plataformas já estabelecidas na China, que contam com uma ampla base de usuários, nota-se o desenvolvimento de aplicativos de pagamentos de importantes marcas de tecnologia, como é o caso do Apple Pay, do Samsung Pay, do Google Pay, assim como de uma ferramenta que pode ser incorporada à rede social Facebook e funcionaria como uma espécie de carteira digital atrelada ao site, que dinamizaria as plataformas de compra e venda dentro da própria rede social. Convém comentar que em 30/03/2021 o Banco Central do Brasil autorizou o Facebook a funcionar como um iniciador de pagamentos a partir de "dois arranjos de pagamento classificados como abertos de transferência, de depósito e pré-pago, domésticos" - Visa e Mastercard - para que sejam realizadas transferências entre pessoas usando o WhatsApp (BCB, 2021). Ademais, segundo Moreira (2021), as bandeiras de cartões fazem parte dos arranjos de pagamentos que vão viabilizar o novo sistema. "Essas empresas, assim como a Cielo e os emissores Banco do Brasil (BB), Nubank e Sicredi, compõem o acordo com o Facebook, que num segundo momento será estendido a outros participantes." Ainda segundo a autora, este "seria um tipo de transação inédito no Brasil já que os cartões são destinados apenas a pagamentos e não a transferências - estas são feitas por meio de TEDs, DOCs e do Pix, operações que usam os "trilhos" dos bancos".

Retornando ao cenário brasileiro, recentemente o Banco Central inaugurou o Pix, ferramenta para a realização de pagamentos instantâneos, que está disponível desde novembro de 2020. De acordo com o Banco Central, o Pix tem como objetivo potencializar a eficiência e a competitividade do mercado nacional, assim como também baixar os custos e aumentar a segurança e a inclusão financeira através da evolução tecnológica atual. Cabe pontuar que não se trata de um aplicativo, mas de uma plataforma que viabiliza a realização de transferências bancárias, ou seja, um meio a partir do qual os bancos (tanto os tradicionais, como fintechs) permitem transferências e pagamentos instantâneos.

Ademais, essa nova ferramenta, cuja responsabilidade se encontra centralizada no Banco Central do Brasil, pode causar mudanças relevantes no cenário de pagamentos, afinal, a praticidade é evidente e as vantagens são muito maiores do que apenas as isenções em transferências. Estima-se que o Documento de Ordem de Crédito (DOC) e a Transferência Eletrônica Disponível (TED), que apresentam custos elevados, podem (e devem) ser em grande medida substituídos pelo uso do Pix (MOTA, 2020). Sobre o Pix, disponibilizado pelo Banco Central em 2020, não são muitos os trabalhos acadêmicos que versam sobre a ferramenta até o presente momento, mas é nítido que a plataforma vem sendo entendida como sinônimo de uma nova era dos pagamentos móveis digitais no Brasil e suas implicações no território podem ser diversas, exigindo uma análise cuidadosa e aprofundada ao longo dos próximos anos.

Além desse recém-inaugurado canal para transferências e pagamentos digitais, vale mencionar que há também exemplos de empresas voltadas justamente ao oferecimento de serviços de pagamentos digitais. Este é o caso do PicPay e do PagSeguro, empresas de destaque no cenário nacional e idealizadas no país, além de 
empresas internacionais que atuam em solo brasileiro, tendo no PayPal seu maior expoente. Esta última, mais recentemente, aumentou sua oferta de serviços ao anunciar em 30 de março de 2021 que permitirá que clientes dos EUA paguem em qualquer lugar do mundo com Bitcoins, ou seja, começará a aceitar criptomoedas como meio de troca para seus milhões de comerciantes globais. Acredita-se que o novo sistema contenha uma estrutura de verificação para as criptomoedas, em que os usuários possam pagar com criptomoedas por bens e serviços em fornecedores previamente aprovados. O PayPal fará com que os comerciantes recebam valores equivalentes diretamente em moeda fiduciária, já que depois que os usuários transferem suas criptomoedas, o sistema realiza uma conversão rápida das moedas (IRRERA, 2021). Cabe ressaltar que todos esses exemplos não são nosso objeto de estudo nesse momento, mas são pertinentes ao trabalho pois, apesar de diversos, ilustram o mesmo processo de digitalização das finanças e serviços bancários.

Estamos presenciando um momento de ebulição no desenvolvimento, popularização e consolidação dessas novas formas de pagamentos digitais e, justamente por isso, a tarefa de se analisar a evolução das empresas de pagamento automático de pedágios em conjunto com a evolução e dos desdobramentos dos pagamentos móveis no Brasil é tão complexa quanto atual. Os exemplos presentes em outros países mostram a dificuldade em se apontar uma trajetória homogênea desse processo, visto que cada país teve suas próprias limitações e especificidades de acordo com as características da base de usuários e das empresas fornecedoras desse serviço (KIM, MIRUSMONOV, LEE, 2010; DAHLBERG et al., 2008; MALLAT, 2007). Contudo, entendemos que mesmo nesse momento de desenvolvimento a interpretação desses processos nos possibilita uma visão prospectiva sobre a atuação dos agentes financeiros nos diferentes usos do território brasileiro.

\section{Os pagamentos móveis e as empresas de pagamento automático de pedágios}

A criação de novos canais de pagamento redefiniu, e segue redefinindo, todos os procedimentos envolvidos nessa cadeia, produzindo uma expansão e uma nova etapa financeira nos usos do território, que se ancoram cada vez mais em bases e serviços móveis digitais. Consequentemente, com o desenvolvimento dos novos sistemas de pagamentos há uma nova dinamização da esfera financeira, em que a digitalização monetária se impõe como pedra fundamental. Nesse sentido, a evolução dessas engenharias dos novos modos digitais de pagamento produz uma complexa rede de cooperação, tecnologia e capital entre os agentes hegemônicos (CREUZ, 2019, p. 432).

No ano de 2020, segundo dados obtidos junto à Agência de Transporte do Estado de São Paulo (ARTESP) por meio de acesso ao SIC - Serviço de Informação ao Cidadão do governo paulista, constata-se que $60 \%$ dos motoristas se utilizaram de modos automáticos de pagamento nas praças de pedágios. Vale pontuar que as formas automáticas de pagamento de pedágios apresentam sucessivas taxas de crescimento no que diz respeito ao percentual de utilização das pistas automáticas em comparação com as pistas de arrecadação manual nos últimos três anos, exemplo disso é que no ano de 2018 a ARTESP registrou uma taxa de 57,27\% de pagamentos automáticos, número que passou para 58,46\% em 2019 (e que atualmente superou a marca de 60\%). Além disso, das cinco grandes empresas do setor, a Sem Parar é aquela que concentra o maior número de TAGs (etiquetas que viabilizam esta forma de pagamento) ativos (2.248.916), seguida pela Veloe (360.222), ConectCar (333.391), Taggy (94.420) e Move Mais (48.528).

Com os avanços dos serviços de pagamentos móveis, oferecidos tanto por novos agentes como também por outros mais consolidados, nota-se uma aproximação entre o campo do mobile payment com o pagamento automático de pedágios. Através dos diferentes planos oferecidos pelas empresas em questão, nota-se a tendência, e até mesmo a necessidade, que estas têm em ampliar suas funções para expandir a base de usuários desse produto, de tal modo que é cada vez mais comum que existam parcerias entre as empresas do gênero com marcas de outros segmentos, como postos de combustíveis e restaurantes franqueados com drive-thru, sem contar o uso em estacionamentos urbanos e shoppings.

O Sem Parar não é apenas a maior empresa do ramo como também a pioneira no Brasil. A startup criada em 2000 foi comprado pela Fleetcor Technologies - grande empresa de pagamentos norte-americana - em março de 2016. Ademais, foi o Sem Parar quem iniciou a ampliação das atividades de pagamentos com as TAGs e atualmente funciona como meio de pagamento em estacionamentos, shoppings, restaurantes franqueados com drive-thru e postos de combustíveis da rede Shell.

Dentre as outras empresas destaca-se o ConectCar. A segunda marca mais relevante do setor apresenta uma forma de contratação diferenciada da anterior e tem sua estrutura acionária composta por dois agentes importantes do sistema bancário-financeiro nacional, o grupo Itaú Unibanco - que comprou 50\% do capital 
da empresa por R\$ 170 milhões em 2015 (ITAÚ S.A., 2015) - em conjunto com o Grupo Ultrapar, que também controla a rede de postos de combustíveis Ipiranga. Além dessas duas empresas, que juntas somam cerca de $94 \%$ de todo o segmento, outras marcas, mais recentes, vêm ampliando seus esforços para angariar um maior número de clientes, investindo em estratégias que possibilitem um produto cada vez mais amplo e diversificado em seus respectivos campos de atuação.

Nesse sentido, dois casos se destacam e permitem associações mais visíveis do que as outras empresas de pagamento automático e eletrônico de pedágios aos serviços de pagamentos móveis. Taggy e Veloe, as mais recentes do setor, se constituem em casos diferentes das demais e permitem analisar distintas tendências nas dinâmicas das empresas de pagamentos automático de pedágios, bem como a inserção destas no campo dos pagamentos móveis de modo mais geral.

$\mathrm{O}$ caso da Veloe merece destaque por fazer parte da joint venture - que basicamente se caracteriza pela associação entre duas empresas - EloPar, que tem sua estrutura acionária dividida por dois bancos tradicionais no cenário nacional, o Banco do Brasil e o Bradesco. Além disso, a joint venture em questão tem na Veloe um mecanismo de ampliação dos investimentos com o serviço de pagamentos eletrônicos no setor de mobilidade, de tal modo que a empresa supracitada faz parte de um conjunto de produtos de meios eletrônicos de pagamentos. Além da Veloe, este portfólio conta com o cartão Elo, com o Alelo, o Livelo e o Digio, um novo banco digital.

Já o Taggy, operadora de pagamentos eletrônicos e automáticos mais recente, se diferencia das demais logo de início, pois oferece uma forma de adesão diferente das outras empresas. Em suma, o Taggy é um serviço white label, ou seja, o produto é desenvolvido por uma empresa e comercializado por outras. Atualmente, o principal parceiro e revendedor do Taggy é o C6Bank, banco digital fundado em 2018, que disponibiliza cartões de crédito, débito e outros serviços financeiros. Além desse banco digital, o Taggy segue incorporando parceiros, são eles: a Zul+, empresa de pagamento automático de pedágios; a Eucard Tag, empresa de pagamento de pedágios que atende pessoas físicas, pessoas jurídicas e frotas de veículos; a e-FRETE, marca dedicada aos sistemas de gestão remota de pagamento de fretes e controle de frotas com rastreamento e gerenciamento das demais despesas; a EcoTaggy, empresa de pagamento automático de pedágios destinada aos motoristas que transitam pelas rodovias administradas pelo grupo Ecorodovias; a AsteroidePass, empresa de pagamento de pedágios; a PlusFrota, que atua como sistema de gestão de frotas e; a MyPass, que além do pagamento automático das cancelas oferece serviços variados de assistência aos motoristas.

Para além desses dois casos, que se diferenciam dos demais pelas características apresentadas, as outras empresas do ramo de pagamento automático de pedágio se aproximam das empresas de mobile payment na medida em que também possibilitam pagamentos móveis. Estes pagamentos também são viabilizados através de tecnologias de mobilidade digital - no caso a etiqueta presente nos para-brisas dos veículos - tal como proposto na definição de Cernev (2010). Conforme exposto, apesar de algumas empresas apresentarem diferenças importantes, todas se enquadram como meios de viabilizar, e alavancar, a categoria dos pagamentos móveis.

Dito isso, compreendemos que as empresas Sem Parar, Veloe, ConectCar, Move Mais e Taggy não se enquadram como empresas de mobile payment propriamente ditas, pois os pagamentos dessas empresas não são efetuados exatamente a partir de um smartphone ou tablet, como sugere a literatura científica sobre o tema. Muito mais importante do que afirmar ou não se estas empresas se enquadram na definição é explorar as aproximações entre elas e o campo dos pagamentos móveis, afinal de contas os pagamentos são efetuados através de uma etiqueta presente no para-brisa, sem a necessidade de utilização de dinheiro físico ou cartão de crédito no momento da compra. Por fim, vale pontuar que os telefones celulares são uma parte importante do processo, toda a administração do dinheiro e das recargas se dá através dos respectivos aplicativos dessas empresas, funcionando como um elemento-chave que permite toda a operação.

Destarte, nota-se uma relação cada vez mais complexa entre os usos do território e a atuação das finanças, que se apresentam de modo mais sofisticado e diversificado. As novas ferramentas de pagamentos móveis e as empresas de pagamento automático de pedágios são exemplos práticos disso. Nota-se que estas empresas se aproximam e estabelecem vínculos estreitos com os bancos, sobretudo os novos bancos digitais (como é o caso do C6Bank e do Digio). Entendemos que esse processo é um dos reflexos da dinamização dos interesses financeiros no período atual, em que a informação se constitui como vetor fundamental da atuação.

Portanto, com o passar do tempo houve uma dupla expansão das empresas de pagamento eletrônico de pedágios que se caracteriza tanto pela expansão de mercado - pois as empresas buscam angariar clientes que transitam por rodovias, mas que também transitam por diversos espaços urbanos como estacionamentos urbanos, shoppings e restaurantes com drive-thru -, como também pela expansão de função, afinal estas 
empresas se transformaram em meios de pagamentos para outras atividades, e seguem buscando a ampliação para novos campos de atuação (como o abastecimento do veículo em postos de combustíveis, por exemplo). Evidenciando novamente a aproximação entre as empresas do setor supracitado com os pagamentos móveis e eletrônicos em geral.

\section{Considerações finais}

Este texto buscou versar sobre o recente fenômeno dos pagamentos móveis, que segue crescendo no Brasil, e apresentar suas principais características. Objetivamos expor algumas questões fundamentais sobre a expansão dos pagamentos móveis e dos canais digitais de serviços financeiros, como é o caso do mobile baking e do mobile payment.

Conforme definido e discutido anteriormente, as formas móveis de pagamento podem ser compreendidas como "pagamentos realizados e/ou viabilizados por meio de tecnologias de mobilidade digital, via dispositivos móveis (CERNEV, 2010, p. 125). Assim, muito mais relevante do que discutir se as empresas de pagamento automático de pedágio se enquadram ou não dentro da definição proposta é buscar os pontos de aproximação entre ambos. Se por um lado o pagamento realizado pelas empresas de pagamentos de pedágio não é centrado em um telefone celular, por outro os smartphones são partes fundamentais do processo, pois alocam os meios de gerenciamento e recarga - que muitas vezes se constituem em verdadeiras carteiras digitais. Ademais, os pagamentos não são efetuados via telefone celular, mas pela leitura da etiqueta presente no para-brisa do veículo, conferindo muito mais dinamismo ao processo, que não envolve cartão de crédito e dinheiro em espécie no momento de realização da compra.

Um ponto que merece destaque reside no fato em que as empresas de pagamento automático e eletrônico estão seguindo uma lógica muito mais ampla do que aquela apenas voltada apenas ao público que trafega constantemente por estradas pedagiadas. A digitalização dos serviços bancários e de pagamentos é uma tendência no Brasil e no mundo, conforme destacado ao longo desse trabalho, e junto a isso devemos acrescentar os investimentos dos bancos (tanto os tradicionais como também os recentes) em tecnologia bancária, que se constitui em mais um ponto que desnuda este movimento.

Com a digitalização dos produtos bancários e a popularização dos meios eletrônicos de pagamento a atuação das finanças segue se capilarizando. Logo, podemos apontar que as empresas de pagamento automático de pedágio buscam uma dupla expansão, que abrange tanto a expansão do seu mercado de usuários (ofertando cada vez mais planos urbanos, com acesso aos shoppings, estacionamentos, postos de gasolina e restaurantes com drive-thru), como também em função, já que a tendência observada é que estas empresas se constituam em empresas de pagamentos móveis de modo geral.

De acordo com nossa leitura, a evolução da tecnologia e das técnicas informacionais, calcadas tanto em aspectos materiais e imateriais, permitiram a digitalização de diversos hábitos, e aqui cabe destacar principalmente aqueles relacionados ao consumo. Atualmente, os telefones celulares são uma ferramenta de extrema importância, pois é através desse objeto técnico que realizamos inúmeras atividades cotidianas, de tal modo que hoje o smartphone é um mediador entre os usuários de diferentes estratos da sociedade brasileira e o desenvolvimento tecnológico em conjunto com técnicas de complexidade crescente que se inserem (desigualmente) na vida socioeconômica e no ordenamento territorial.

Os interesses e perspectivas sobre o desenvolvimento desse fenômeno são diversos: no que diz respeito ao cotidiano socioeconômico da população brasileira, as instituições bancárias tradicionais, por exemplo, almejam uma maior inclusão financeira e bancarização da população brasileira por meio dos fenômenos supracitados, já o Banco Central, por meio do Pix, busca revolucionar os meios de pagamento através dessa plataforma digital e instantânea que iniciou suas operações recentemente. Já no que tange ao planejamento territorial um amplo debate pode ser feito se considerarmos a difusão seletiva dos objetos técnicos mais modernos pelo território nacional, sobretudo aqueles associados com as mais novas tecnologias que envolvem a infraestrutura para funcionamento da internet. Ou seja, para que um pleno sistema de pagamentos digitais se concretize em todo o território nacional, haveria a necessidade de dotá-lo de uma rede informacional mais difusa e eficiente. Tal fato foi buscado com o Plano Nacional de Banda Larga (PNBL) na década de 2010 e no início da década de 2020 com as promessas a partir do leilão para implantação da internet $5 \mathrm{G}$ no Brasil. Cabe destacar que este objetivo de reduzir as áreas do território que carecem de uma alta densidade técnica e informacional trata-se de um esforço no sentido de adaptar o território nacional para sua adequação à lógica de funcionamento do mercado global que demanda internet com velocidades cada vez mais altas (COSTA, GALLO, 2020). Ou, conforme Steda (2012, p. 72): "Trata-se, na realidade, de um processo de integração financeira do território (interna e externamente)". 
Nosso objetivo foi apresentar uma leitura sobre um fenômeno que se manifesta de múltiplas formas. A presença de grupos bancários tradicionais e de bancos digitais criados recentemente nas estruturas acionárias das empresas de pagamento automático e eletrônico de pedágios nos permitem estabelecer estes pontos, que visam contribuir com os avanços de leituras geográficas sobre os processos discutidos ao longo do texto. Se por um lado as finanças se apresentam como cada vez mais fluídas, autônomas e digitais, por outro isso não se dá de modo desterritorializado e a leitura geográfica é fundamental nos intentos de compreensão.

Por fim, ponderamos que essa nova etapa de digitalização financeira reflete uma preocupação geográfica dos bancos, tendo em vista que através desses novos meios podem atingir e bancarizar novos contingentes de pessoas, operando com custos reduzidos e ampliando seus graus de capilaridade pelo território. Seguramente, a capilarização desses serviços através de novas plataformas de âmbito digital não se realizam fora do território, mas são viabilizadas por uma série de fatores materiais e imateriais em que o espaço geográfico interfere, em conjunto com outras instâncias, de modo ativo.

\section{Referências bibliográficas}

ABRAHÃO, R. S. Intenção de adoção do mobile payment: uma análise à luz das teorias de aceitação e uso de tecnologia. Dissertação (Mestrado em Administração). Universidade Federal de Uberlândia. Uberlândia, 2015.

ALBUQUERQUE, J.P.; DINIZ, E. H.; CERNEV, A. K. Mobile payments: a scoping study of the literature and issues for future research. Information Development, Thousand Oaks, CA, SAGE Publications, v. 32, 2015. https://doi.org/10.1177/0266666914557338

BCB - Banco Central do Brasil. BC autoriza dois arranjos e uma instituição de pagamentos relacionados ao WhatsApp. Disponível em: https://www.bcb.gov.br/detalhenoticia/17359/nota. Acesso em 05 abr. 2021.

BERTOLLO, M. A capilarização das redes de informação no território brasileiro pelo smartphone. 2019. 241 f. Tese (Doutorado em Geografia Humana) - Faculdade de Filosofia, Letras e Ciências Humanas, Universidade de São Paulo, São Paulo, 2019.

CERNEV, A. K. Mobile banking no Brasil: eventos críticos, trajetória e cenários esperados. 2010. 378 f. Tese (Doutorado) - Curso de Administração, Escola de Administração de Empresas de São Paulo, Fundação Getúlio Vargas, São Paulo, 2010.

CHESNAIS, F. Mundialização: o capital financeiro no comando. Revista Outubro. São Paulo, n. 5, p. 7-28, 2000.

CONTEL, F. B. Território e finanças: Técnicas, normas e topologias bancárias no Brasil. Tese (Doutorado em Geografia) - Departamento de Geografia, Universidade de São Paulo, São Paulo, 2006.

COSTA, B. M. R.; GALLO, F. Inflexão do Programa Nacional de Banda Larga (PNBL) e aprofundamento das desigualdades socioespaciais no Brasil. Formação (Online), v. 27, n. 51, p. 33-64, 2020.

CREUZ, V. División financiera del trabajo em sistemas de pagos en Argentina y Brasil. Revista Geográfica Venezolana, Mérida, v. 60, n. 2, p. 430-445, 2019.

DAHLBERG, T. et al. Past, present and future of mobile payments research: a literature review. Eletronic Commerce Research and Applications, v. 7, p. $165-181,2008$. https://doi.org/10.1016/j.elerap.2007.02.001

FEBRABAN - FEDERAÇÃO BRASILEIRA DE BANCOS. Pesquisa FEBRABAN de Tecnologia Bancária 2013. Elaborada por: Strategy\&, 2013. Disponível em: https://cmsportal.febraban.org.br/Arquivos/documentos/PDF/Pesquisa\%20FEBRABAN\%20de\%20Tecnolog ia\%20Bancaria_2013.pdf. Acesso em 10 abr. 2021.

FEBRABAN - FEDERAÇÃO BRASILEIRA DE BANCOS. Pesquisa FEBRABAN de Tecnologia Bancária 2019. Elaborada por: Deloitte, 2019. Disponível em: 
https://cmsportal.febraban.org.br/Arquivos/documentos/PDF/Pesquisa-FEBRABAN-Tecnologia-Bancaria2019.pdf. Acesso em 10 abr. 2021.

HARVEY, D. O neoliberalismo: história e implicações. São Paulo: Loyola, 2008.

IRRERA, A. Exclusive: PayPal launches crypto checkout service. Reuters (online), 31 mar. 2021. Disponível em: https://www.reuters.com/article/crypto-currency-paypal-idUSL1N2LR0OD. Acesso em 06 abr. 2021.

ITAÚ S. A. Relatório Anual 2015. São Paulo: Editora Contadino, 2015.

JORGE, R. R. et al. O ecossistema de Fintechs no Brasil. Revista de Casos e Consultoria, Natal, v. 9, n. 3, 2018.

KAHIL, S. P. Psicoesfera: uso corporativo da esfera técnica do território e o novo espírito do capitalismo. Estudos Geográficos, v. 10, n. 2, p. 10-25, 2013.

KIM, C.; MIRUSMONOV, M.; LEE, I.; An empirical examination of factors influencing the intention to use mobile payment. Computers in Human Behavior, v. 26, n. 3, p. 310-322, 2010. https://doi.org/10.1016/j.chb.2009.10.013

MALLAT, N. Exploring counsumer adoption of mobile payment - a qualitative study. The Journal of Strategic Information Systems, v. 16, n. 4, p. 413-432, 2007. https://doi.org/10.1016/j.jsis.2007.08.001

MOLNAR NETO, F. Mobile payment e o caso da Paggo no Brasil. Dissertação (Mestrado em Administração) - Escola de Administração de Empresas de São Paulo. Fundação Getúlio Vargas, FGV, São Paulo, 2013.

MOREIRA, Talita. WhatsApp permitirá transferência via cartões. Valor Econômico (online) 31 mar. 2021. Disponível em: https://valor.globo.com/financas/noticia/2021/03/31/whatsapp-permitira-transferencia-viacartoes.ghtml. Acesso em: 05 abr. 2021.

MOTA, C. V. Pix: como novo meio de pagamento desafia indústria de cartões, maquininhas e grandes bancos. BBC News Brasil. 29 set. 2020. Disponível em https://g1.globo.com/economia/noticia/2020/09/29/pix-como-novo-meio-de-pagamento-desafia-industria-decartoes-maquininhas-e-grandes-bancos.ghtml. Acesso em 30 de set. 2020.

SANTOS, M. A natureza do espaço: técnica e tempo, razão e emoção. São Paulo: EDUSP, 2002. (Coleção Milton Santos; 1).

SANTOS, M. et al. O Papel Ativo da Geografia - Um Manifesto. Apresentado pelo Laboratório de Geografia Política e Planejamento Territorial e Ambiental, do Departamento de Geografia - Faculdade de Filosofia, Letras e Ciências Humanas da Universidade de São Paulo (USP) no XII Encontro Nacional de Geógrafos. Florianópolis, julho de 2000. Anais...

SANTOS, M. Por uma outra globalização: do pensamento único à consciência universal. 6 ed. Rio de Janeiro: Record, 2001.

SANTOS, M.; SILVEIRA, M. L. O Brasil: território e sociedade no início do século XXI. 9 ed. Rio de Janeiro: Record, 2006.

STEDA, M. M. V. Políticas do Estado e políticas das empresas: um estudo sobre a internet de banda larga no Brasil. 81 f. Monografia (Graduação em Geografia) - Instituto de Geociências, Universidade Estadual de Campinas, Campinas: 2012.

VIDEIRA, S. L. Fintechs - novos atores das finanças contemporâneas: um olhar geográfico. Entre-Lugar, v. 11, n. 21, p. 261-284, 2020. 
WARF, B. Digitalização, globalização e capital financeiro hipermóvel. Geousp - Espaço e Tempo (online), v. 21, n. 2, p. 397-406, 2017. https://doi.org/10.11606/issn.2179-0892.geousp.2017.135154

$10 \begin{aligned} & \text { Este artigo é distribuído nos termos e condições do Creative Commons Attributions/Atribuição- } \\ & \text { NãoComercial-CompartilhaIgual (CC BY-NC-SA). }\end{aligned}$ 